\title{
Noninvasive mechanical ventilation with BiPAP therapy for comatose exacerbation of chronic obstructive pulmonary disease through an endotracheal tube: is it justified?
}

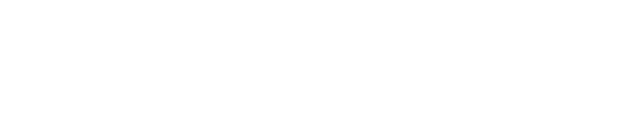

\author{
Antonio Esquinas' \\ Ritesh Agarwal ${ }^{2}$ \\ 'Intensive Care Unit, Hospital Morales \\ Meseguer, Murcia, Spain; ${ }^{2}$ Department \\ of Pulmonary Medicine, Postgraduate \\ Institute of Medical Education and \\ Research, Chandigarh, India
}

We read with interest the paper by Rawat et al ${ }^{1}$ related to the role of bilevel positive airway pressure (BiPAP) delivered via endotracheal tube in unconscious patients suffering from acute exacerbations of chronic obstructive pulmonary disease in a real-world situation. Although the authors provide some justification for the use of BiPAP through an endotracheal tube, we believe that this technique is fraught with complications and should not be routinely employed. In fact, three patients failed BiPAP therapy, two patients received conventional invasive ventilation, and one patient failed to respond to BiPAP. Thus, almost $30 \%$ of patients either failed or showed no evidence for benefit of BiPAP. Further, the authors provide no data on the amount of leakage that was present while administering BiPAP therapy. The authors also do not provide details on whether the nurses/chest therapist administered intermittent manual bag ventilation. Ideally, the authors should have referred the patients on manual bag ventilation to another public health center where facilities for invasive ventilation are available free of cost.

From a physiological standpoint, assist-control mode is preferred in patients with severe acidosis and exacerbation of chronic obstructive pulmonary disease. The BiPAP mode has advantages only with an intact drive (not apnea). Thus, in patients with a decreased level of consciousness or apnea, we may suppose that the assist-control mode is more effective for achieving effective muscular rest and ventilation, as shown by Nava et al. ${ }^{2}$ Application of high positive pressures alone does not guarantee an adequate tidal volume. ${ }^{3}$ Moreover, there is no definite relationship between high pressure levels and adequate washout of $\mathrm{pCO}_{2}$. Finally, the authors provide no explanation regarding the failure of therapy in nonresponders, but believe that the device delivered an adequate amount of positive pressure.

In summary, although this study provides evidence for a new treatment strategy in patients with a low level of consciousness, we believe that this should only be considered after appropriate assessment of the risks and benefits of this practice and further evidence from animal/experimental models that such equipment is safe and efficacious.

\section{Disclosure}

The authors report no conflicts of interest in this work.
Correspondence: Antonio Esquinas Intensive Care Unit, Hospital Morales Meseguer, Avenida Marques de los velez s/n Murcia, 30008, Spain

Tel +34609321966

Fax +34968232484

Email antmesquinas@gmail.com 


\section{References}

1. Rawat J, Sindhwani G, Biswas D, Dua R. Role of BiPAP applied through endotracheal tube in unconscious patients suffering from acute exacerbation of COPD: a pilot study. Int J Chron Obstruct Pulmon Dis. 2012;7:321-325.

2. Nava S, Ambrosino N, Clini E, et al. Noninvasive mechanical ventilation in the weaning of patients with respiratory failure due to chronic obstructive pulmonary disease. A randomized, controlled trial. Ann Intern Med. 1998;128:721-728.

3. Dreher M, Storre JH, Schmoor C, Windisch W. High-intensity versus low-intensity non-invasive ventilation in patients with stable hypercapnic COPD: a randomised crossover trial. Thorax. 2010;65: 303-308. 


\section{Authors' response}

\author{
Jagdish Rawat \\ Girish Sindhwani
}

Department of Pulmonary Medicine, Himalayan Institute of Medical Sciences, Swami Ram Nagar, Jollygrant, Dehradun, Uttarakhand, India

Correspondence: Jagdish Rawat

Department of Pulmonary Medicine, Himalayan Institute of Medical

Sciences, Swami Ram Nagar, Jollygrant, Dehradun 248I40, India

Tel +9| I3 5247 |362

Fax +9l 135247 I3I7

Email drjagdishrawat@yahoo.com

We are grateful to Drs Esquinas and Agarawal for their comments regarding safety and outcomes issues associated with bilevel positive airway pressure (BiPAP) applied through an endotracheal tube in unconscious patients suffering from acute exacerbations of chronic obstructive pulmonary disease. In our study, only one patient developed pneumonia but survived, and two patients were shifted to the intensive care unit during the course of BiPAP therapy owing to subsequent availability of funds, and hence both patients were excluded from the final analysis. Inhospital mortality in our study was $15 \%(3 / 20)$, which is far lower than that in the mechanically ventilated patients with chronic obstructive pulmonary disease reported by Chandra et $\mathrm{al}^{1}$ (30\%), Ai-Ping et al ${ }^{2}(25 \%)$, Raurich et $\mathrm{al}^{3}(25 \%)$, and Seneff et $\mathrm{al}^{4}(24 \%)$.

Another issue raised was regarding leaks while administering BiPAP therapy. We connected the endotracheal tube to BiPAP via a connector with two ends, one end to the endotracheal tube and the other end to a BiPAP hosepipe. Expiratory and oxygen ports were made manually. This mechanism ensured a strongly leak-proof system.

Another issue raised concerned referral of these patients to public sector hospitals. In India, the majority of government sector hospitals do not have facilities for ventilation, and there are cost constraints for poor patients at private sector hospitals. We agree that conventional BiPAP through an endotracheal tube is not the best option for patients with decreased levels of consciousness, and hybrid ventilators delivering both pressure and volume preset ventilation with other features like assisted-control mode, an alarm, and battery backup, would be a better choice, as we have already mentioned in the Discussion section of the original paper.

\section{Disclosure}

The authors report no conflicts of interest in this work.

\section{References}

1. Chandra D, Stamm JA, Taylor B, et al. Outcomes of noninvasive ventilation for acute exacerbations of chronic obstructive pulmonary disease in the United States, 1998-2008. Am J Respir Crit Care Med. 2012;185:152-159.

2. Ai-Ping C, Lee KH, Lim TK. In-hospital and 5-year mortality of patients treated in the ICU for acute exacerbation of COPD: a retrospective study. Chest. 2005;128:518-524.

3. Raurich JM, Perez J, Ibanez J, et al. In-hospital and 2-year survival of patients treated with mechanical ventilation for acute exacerbation of COPD. Arch Bronconeumol. 2004;40:295-300.

4. Seneff MG, Waqner DP, Waqner RP, et al. Hospital and 1-year survival of patients admitted to intensive care units with acute exacerbation of chronic obstructive pulmonary disease. JAMA. 1995;274:1852-1857.
International Journal of COPD

\section{Publish your work in this journal}

The International Journal of COPD is an international, peer-reviewed journal of therapeutics and pharmacology focusing on concise rapid reporting of clinical studies and reviews in COPD. Special focus is given to the pathophysiological processes underlying the disease, intervention programs, patient focused education, and self management protocols

\section{Dovepress}

This journal is indexed on PubMed Central, MedLine and CAS. The manuscript management system is completely online and includes a very quick and fair peer-review system, which is all easy to use. Visit $\mathrm{http}: / / \mathrm{www}$.dovepress.com/testimonials.php to read real quotes from published authors. 